\title{
Modelling and Simulation Techniques for Forced Convection Heat Transfer in Heat Sinks with Rectangular Fins
}

\author{
Hussam Jouhara* \\ School of Engineering and Design, Brunel University, Uxbridge, Middlesex, UB8 3PH, UK, \\ Tel: +44 (0) 1895 267656, Fax: +44 (0) 1895 256392, Email: hussam.jouhara@brunel.ac.uk
}

\author{
Brian P. Axcell
}

Institut Catholique d'Arts et Métiers, 6 rue Auber, 59046 Lille Cedex, France Phone: +44 (0) 1925 267540, Fax: +44 (0) 1925 600139, E-mail: brian.axcell@gmail.com

* Corresponding Author 


\begin{abstract}
This paper provides a comprehensive description of the thermal conditions within a heat sink with rectangular fins under conditions of cooling by laminar forced convection. The analysis, in which increasing complexity is progressively introduced, uses both classical heat transfer theory and a computational approach to model the increase in air temperature through the channels formed by adjacent fins and the results agree well with published experimental data.

The calculations show how key heat transfer parameters vary with axial distance, in particular the rapid changes in heat transfer coefficient and fin efficiency near the leading edges of the cooling fins. Despite these rapid changes and the somewhat ill-defined flow conditions which would exist in practice at the entry to the heat sink, the results clearly show that, compared with the most complex case of a full numerical simulation, accurate predictions of heat sink performance are attainable using analytical methods which incorporate average values of heat transfer coefficient and fin efficiency. The mathematical modelling and solution techniques for each method are described in detail.
\end{abstract}

Keywords: Fins, heat sink, laminar heat transfer, parallel flow.

\title{
1 Introduction
}

Electronic components invariably generate unwanted heat during operation and as electronic systems have become both more compact and more powerful the problem of efficient and reliable heat removal, which is needed for safe operation of the component, has become onerous. Electronic components and assemblies tend to be of a small scale and they are typically cooled by air flowing at moderate velocities. The combination of small dimensions, the use of air as the cooling fluid and low velocities normally results in laminar convection and hence correspondingly low values for heat transfer coefficients.

In general, when gas cooling needs to be enhanced, it is achieved by the use of cooling fins, which increase the surface area available for heat transfer. Extended heat transfer surfaces are often used with electronic systems with fins providing a heat sink for the thermal loading. A typical arrangement for a heat sink with rectangular fins and the air flow direction through the channels are shown in Figures 1 and 2. Heat generated by the electronic component is conducted to a base plate of length $L$, to which cooling fins of height $H$ and width $t$ are attached. Both sides of each fin participate in the cooling process, with convection taking place in the channels of width $b$ formed by adjacent fins.

Although various flow configurations and fin geometries are possible for the cooling process, to date most investigations have considered rectangular fins. Teertstra et al. [1] examined air flow parallel to the base plate; in this case the heat transfer may therefore be represented by convection in a parallel plate channel. Duan and Muzychka [2] considered an impinging flow on the central region of the fin assembly, which then turned through $90^{\circ}$ and exited outwards in both directions through the rectangular channels formed by the cooling fins. Shin [3] also investigated rectangular fins and included cooling by natural convection. Probably the most comprehensive study of the topic to date is provided by Bar-Cohen and Iyengar [4]. The authors considered not only the thermal performance of a heat sink with rectangular fins but also the pumping power required during operation and the material needed for construction in order to provide a "least material" and "least energy" design.

None of the papers published to date, however, appears to have given a comprehensive description of the heat transfer within the heat sink. The heat transfer coefficient and fin efficiency will vary along the flow path because of entry effects for the thermal and momentum boundary layers in the inlet region; in the entrance region heat 
transfer coefficients derived for fully-developed flow are not applicable. In addition the flow will be ill-defined at the entry because of disturbances caused by the bluff nature of the leading edges of the fins. There will also be some axial heat conduction in the fins in the upstream direction.

This paper aims to show how heat transfer principles can be applied to rectangular heat sinks for electronic components. Initially the simplest scenario will be considered, in which the array of cooling fins is isothermal. Then thermal conditions within the heat sink will be modelled by a single, average fin efficiency and an average heat transfer coefficient. Greater complexity will be added using numerical integration by allowing both heat transfer coefficient and fin efficiency to vary along the flow path. Finally the effects of longitudinal conduction in the fins and the effect of flow disturbance at the leading edges of the fins will be modelled in a three-dimensional CFD analysis with a finite element treatment of the cooling fins. It is shown however that the simplest engineering approach using analytical expressions for uniform heat transfer coefficient and fin efficiency gives good accuracy for engineering purposes.

\section{Test cases for calculations}

In order to demonstrate the efficiency of the different modelling and solution techniques, the geometrical arrangement of Teertstra et al. [1] is considered: two identical heat sinks of the form shown in Figure 1 were tested back-to-back. Each heat sink had a length $L=115 \mathrm{~mm}$ and contained 15 fins. The height $H$ of each fin was $49 \mathrm{~mm}$, the thickness $t$ was $1.25 \mathrm{~mm}$ and the gap between fins $b$ was $2.18 \mathrm{~mm}$. The heat sinks were presumably constructed from aluminium because the authors specified a thermal conductivity for the fins $k_{s}$ of $200 \mathrm{~W} / \mathrm{m} \mathrm{K}$.

The heat sink assembly was installed in a wind tunnel with a shroud preventing the air flow from by-passing the assembly. The air approach velocity in the wind tunnel was varied from $1 \mathrm{~m} / \mathrm{s}$ to $8 \mathrm{~m} / \mathrm{s}$; the mean velocity in the flow passages between fins was $87.7 \%$ higher because of a reduced flow area through the heat sinks.

Teertstra et al. [1] performed tests for power inputs from $100 \mathrm{~W}$ to $500 \mathrm{~W}$. When expressed in dimensionless form, their experimental results did not vary significantly with power input. This is because heat sink temperatures are a linear function of power input and experimental Nusselt numbers will not change with power level if the variations in transport properties for air with temperature are small and the contribution of thermal radiation is negligible. Consequently the calculations were restricted for the given range of velocities to a single base plate temperature of $50^{\circ} \mathrm{C}$ for an air inlet temperature of $20^{\circ} \mathrm{C}$. Air properties were evaluated at $300 \mathrm{~K}\left(27^{\circ} \mathrm{C}\right)$.

\section{Theory}

\section{(i) Idealised case}

Initially it is assumed that the fin surfaces are at a uniform temperature $T_{s}$ equal to that of the base plate. The influence of a reduction in fin temperature away from the base plate will be accommodated later, first by the use of a traditional fin efficiency $\eta$ and then in a finite element study. In the analytical treatment of the heat sink, heat transfer correlations for convection from surfaces of uniform temperature will be utilised because this boundary condition represents most closely the case under examination.

Consider a flow in the channel between two fins having a mean velocity $u_{m}$ and a local bulk mean temperature $T_{b}$. In a length of the flow channel $d x$ the bulk mean temperature increases by an amount $d T_{b}$ given by: 


$$
q P d x=\rho u_{m} A c_{p} d T_{b}
$$

where $P$ is the perimeter of the heated surface, $A$ is the flow area, $\rho$ and $c_{p}$ are respectively the density and specific heat capacity of the air flow and the heat flux $q$ is related to the local temperature difference $T_{s}-T_{b}$ by the local heat transfer coefficient $h$ :

$$
q=h\left(T_{s}-T_{b}\right)
$$

Denoting the local temperature difference by the symbol $\theta$; $\left(\theta=T_{s}-T_{b}\right)$, equation (1) can be rewritten

$$
\frac{d \theta}{\theta}=-\frac{h P}{\rho u_{m} A c_{p}} d x
$$

Introducing a hydraulic diameter for the flow defined by

$$
D_{h}=4 A / P
$$

the differential takes the form:

$$
\frac{d \theta}{\theta}=-\frac{4 h}{\rho u_{m} c_{p} D_{h}} d x
$$

It should be noted that for a flow channel in which $H / b>>1$, the hydraulic diameter $D_{h}$ is simply twice the gap $2 b$ and this value will be used in all of the calculations. The heat transfer from the base plate will be added to that from the side walls.

Finally we introduce a dimensionless length scale $x^{*}$ defined by

$$
x^{*}=\frac{x}{\operatorname{Re} \operatorname{Pr} D_{h}}
$$

where Re and $P r$ are the Reynolds number and Prandtl number, respectively.

Equation (5) can then be written in terms of a local Nusselt number, $N u=\frac{h \cdot D_{h}}{k}$ :

$$
\frac{d \theta}{\theta}=-4 N u d x^{*}
$$

Integrating from the entrance of the flow channel where $x^{*}=0$ to a particular value of $x^{*}$ :

$$
\ln \left(\theta / \theta_{0}\right)=-4 \int_{0}^{x^{*}} N u d x^{*}
$$

or

$$
\frac{\theta}{\theta_{0}}=\exp \left\{-4 \int_{0}^{x^{*}} N u d x^{*}\right\}
$$

Since the mean value of the Nusselt number for a length $x$ can be defined by 


$$
N u_{m}=\frac{1}{x^{*}} \int_{0}^{x^{*}} N u d x^{*}
$$

equation (9) can be written in the form:

$$
\frac{\theta}{\theta_{0}}=\exp \left\{-4 N u_{m} x^{*}\right\}
$$

The rate of heat removal from all channels formed by adjacent fins can then be calculated from the change in the temperature difference $\theta$ :

$$
Q=N \rho u_{m} A c_{p}\left(\theta_{0}-\theta_{L}\right)
$$

It is also possible to define the rate of heat removal from the heat sink to the temperature difference at inlet:

$$
Q=N \rho u_{m} A c_{p} \theta_{0}\left[1-\exp \left(-4 N u_{m} L^{*}\right)\right]
$$

in which $L^{*}$ corresponds to the value $x^{*}$ at the end of the flow channels.

This expression also provides a limit for the maximum rate of heat removal for a given flow, since if the length is sufficiently large, the exponential term is negligible.

In order to use equation (13) one requires either a mean Nusselt number or an expression from which the mean value can be evaluated. The development of the heat transfer coefficient in such passages however is a complex process.

When the cooling flow enters a channel formed by two adjacent fins, thermal and momentum boundary layers begin to grow on the heat transfer surfaces. Close to the leading edge local heat transfer coefficients have high values because small thermal resistance to the convective process is presented by the thin boundary layers. At the leading edge itself the heat transfer coefficient is, in theory, infinite. As the boundary layers grow in size the heat transfer coefficient decreases with distance; in a region in which the boundary layer thicknesses are small compared with the gap between adjacent fins it may be determined from [5]:

$$
N u_{x}=h x / k=0.332 \operatorname{Re}_{x}^{1 / 2} \operatorname{Pr}^{1 / 3}
$$

in which the length scale in the Nusselt number and Reynolds number is $x$, the distance from the leading edge, and the heat transfer coefficient is based on $\theta_{0}$, the difference between the fin surface temperature and the air inlet temperature.

As the boundary layer thicknesses become significant in terms of the gap $b$, the flow takes on more of the characteristics of an internal flow. Eventually the boundary layers meet at the centre of the channel and as soon as the shape of velocity and temperature profiles cease to change, the local heat transfer coefficient is given by a fully-developed value, defined in dimensionless terms by the following simple equation [6]:

$$
N u=7.54
$$


It can be seen from equation (11) that, in the region of fully-developed heat transfer, when the Nusselt number is a constant, the bulk mean temperature for the air, $T_{b}$, approaches $T_{s}$, the value of the fin surface temperature, exponentially. Hence strictly the air temperature reaches the surface temperature only in a flow channel of infinite length.

No analytical solutions for mean Nusselt number cover the full range of heat transfer development from boundary layer flow at the leading edge to fully-developed internal heat transfer, many hydraulic diameters downstream. However Hwang and Fan [7] have performed a numerical analysis for laminar heat transfer in a parallel-sided duct for uniform wall temperature with simultaneously developing velocity and temperature profiles. The following expression fits their data for mean Nusselt number to an accuracy of $3 \%$ for $0.1<\operatorname{Pr}<1000$ :

$$
N u_{m}=7.55+\frac{0.024 x^{*^{-1.14}}}{1+0.0358 \operatorname{Pr}^{0.17} x^{*^{-0.64}}}
$$

This expression may be used to calculate the rate of heat removal from the heat sink for this idealised case using equation (13) above.

\section{(ii) Approximate analysis: heat transfer with non-uniform wall temperatures}

Conduction heat transfer from the base plate into the cooling fins takes place only in the presence of a temperature gradient. Hence fin temperatures decrease with increasing distance from the base plate and the idealised thermal output provided above will overestimate the thermal performance.

Heat transfer from a cooling fin to the surrounding air is often calculated using a fin efficiency $\eta$, which relates the rate of heat transfer from the fin to that which would occur for a fin at a uniform temperature equal to the base plate. The fin efficiency for rectangular fins with zero heat transfer at the tips is given by the following expression [8]:

$$
\eta=\frac{\tanh (m H)}{m H}
$$

where the parameter $\mathrm{m}$ is defined by

$$
m^{2}=\frac{2 h}{k_{s} t}
$$

It is possible to estimate the rate of heat transfer from the heat sink using a mean heat transfer coefficient and a single fin efficiency based on this heat transfer coefficient, even though it is noted that both the heat transfer coefficient and fin efficiency vary along the flow passage.

For a small element of the flow passage between the two adjacent fins of length $d x$ the rate of heat transfer is given by

$$
\delta Q_{1}=h \theta(b+2 H \eta) d x
$$

Equating this to the enthalpy increase of the flow

$$
h \theta(b+2 H \eta) d x=-\rho u_{m} b H c_{p} d \theta
$$

Noting that $h=N u k / D_{h}, \rho u_{m}=\operatorname{Re} \mu / D_{h}$ and $c_{P}=\operatorname{Pr} k / \mu$, and setting $D_{h}=2 b$, the equation may be written in dimensionless form: 


$$
\frac{d \theta}{\theta}=-4\left(\eta+\frac{b}{2 H}\right) \frac{N u}{\operatorname{Re} \operatorname{Pr} D_{h}} d x
$$

which may be integrated for a constant value of $\eta$ to give the temperature difference $\theta$ at outlet $(x=L)$

$$
\frac{\theta_{L}}{\theta_{0}}=\exp \left\{-4\left(\eta+\frac{b}{2 H}\right) N u_{m} x^{*}\right\}
$$

from which the heat removal from the heat sink may be calculated using equation (12).

\section{(iii) Analysis using numerical integration along the flow passage}

As noted above, both the heat transfer coefficient $h$ and the fin efficiency $\eta$ vary along the flow. Consequently better accuracy should be achieved by calculating the increase in bulk temperature using local values for the two parameters. Now, the mean Nusselt number $N u_{m}$ can be defined in terms of the local Nusselt Number $\mathrm{Nu}$ in equation (10). It follows that an expression for the local Nusselt number can be obtained from the equation for the mean Nusselt number by differentiation:

$$
N u=\frac{d}{d x^{*}}\left[x^{*} N u_{m}\right]=N u_{m}+x^{*} \frac{d}{d x^{*}}\left[N u_{m}\right]
$$

Shah and Bhatti [9] performed the differentiation using equation (16) and obtained the following expression for local Nusselt number:

$$
N u=7.55+\frac{0.024 x^{*^{-1.14}}\left[0.0179 \operatorname{Pr}^{0.17} x^{*^{-0.64}}-0.14\right]}{\left[1+0.0358 \operatorname{Pr}^{0.17} x^{*^{-0.64}}\right]^{2}}
$$

Local heat transfer coefficients and local fin efficiencies may be calculated from this expression and again, after including the contribution of the base plate to convective heat transfer, the increase in bulk air temperature can be evaluated in steps along the flow passage. Finally the overall rate of heat removal from the flow passage can again be calculated using equation (12). This essentially was the approach adopted by Bar-Cohen and Iyengar [4] for the thermal analysis in their paper.

\section{(iv) Finite element/ CFD study}

The computational study was performed using Ansys CFX and Ansys Multiphysics software. Symmetry considerations allowed a model to be constructed using a single cooling fin split along the centre line. The boundary conditions on the surfaces, the geometry and the domains can be seen Figure 3.

The computational model comprises two parts: the solid model representing half of a fin (Figure 3), and the fluid model to represent the flow through the heat sink. The fluid model consisted of 401420 hexahedral elements with 100 wedge-shaped elements and the solid mesh consisted of 218270 hexahedral elements and 460 wedge elements. Grid independence was achieved by increasing the number of the elements and plotting the convergence of certain parameters of interest such as free surface velocity, and also tracking 
global parameters such as total rate of heat transfer through the system. The code solved the two dimensional equations for continuity, momentum and energy as follows:

$$
\begin{gathered}
\frac{\partial u}{\partial x}+\frac{\partial v}{\partial y}+\frac{\partial w}{\partial z}=0 \\
\rho\left(u \frac{\partial u}{\partial x}+v \frac{\partial u}{\partial y}+w \frac{\partial u}{\partial z}\right)=-\frac{\partial P}{\partial x}+\mu \nabla^{2} u \\
\rho\left(u \frac{\partial v}{\partial x}+v \frac{\partial v}{\partial y}+w \frac{\partial v}{\partial z}\right)=-\frac{\partial P}{\partial y}+\mu \nabla^{2} v \\
\rho\left(u \frac{\partial w}{\partial x}+v \frac{\partial w}{\partial y}+w \frac{\partial w}{\partial z}\right)=-\frac{\partial P}{\partial z}+\mu \nabla^{2} w \\
u \frac{\partial T}{\partial x}+v \frac{\partial T}{\partial y}+w \frac{\partial T}{\partial z}=\alpha \nabla^{2} T
\end{gathered}
$$

Calculations were made for approach velocities of $2 \mathrm{~m} / \mathrm{s}$ and $4 \mathrm{~m} / \mathrm{s}$, which would respectively generate Reynolds numbers in the flow passages of 1044 and 2088. These values would give laminar flow within the heat sink (see section 5 below). It should be noted in any case that cooling systems are normally designed to operate with Reynolds numbers no greater than about 1000 because of the need to avoid excessive noise.

The calculations were made with a maximum residual of $10^{-5}$ and a maximum of 100 iterations. Sample results for the temperature and velocity profile can be seen in Figures 4 and 5 . Figure 5 shows the edge effect on the approaching flow (the disturbance).

\section{Results}

Results were obtained for each of the approaches outlined in the theory section above. First base-line calculations were performed assuming the cooling fins were at the base plate temperature and hence fin efficiencies were $100 \%\left(Q_{\text {ideal }}\right)$. Then a uniform fin efficiency was employed, based on the mean Nusselt number for the flow in the channel formed between adjacent fins, giving $Q_{a p p r o x}$. Next both heat transfer coefficient and fin efficiency were allowed to vary along the heated length and local conditions established from numerical integration. The thermal output of the heat sink $Q_{n u m}$ could be found by integrating the rate of heat loss from each element or from an overall enthalpy balance. Step lengths of $1 \mathrm{~mm}$ and $5 \mathrm{~mm}$ were investigated, corresponding to axial distances of approximately $0.2 D_{h}$ and $D_{h}$. There was less than a 1\% difference in the cooling performance of the heat sink for the two step lengths in every case and hence the use of a $1 \mathrm{~mm}$ step length was considered sufficiently small. Finally a CFD study was conducted using commercial software for two of the flow rates to give values for $Q_{C F D}$.

The predicted thermal performance of a single heat sink using the four methods of calculation is shown in Table 1 for approach velocities from 1 to $8 \mathrm{~m} / \mathrm{s}$. The rate of heat transfer $Q_{\text {num }}$ calculated by numerical integration along the flow path can be seen to be lower 
than $Q_{a p p r o x}$, the value found using average values of the Nusselt number and fin efficiency, by an amount which varied from almost zero at the lowest flow rate to about $4 \%$ at the highest flow rate. The results from the computational study are marginally higher than those calculated using from the approximate calculations, the discrepancies being $3 \%$ for the lower flow rate and $1 \%$ for the higher flow rate.

Other heat transfer parameters are also given in Table 1: the mean velocity in the flow passage, the Reynolds number for the flow passage, the mean Nusselt number, the fin efficiency based on the mean Nusselt number and the air outlet temperature found by numerical integration. Figure 6 shows the output from the heat sink graphically as a function of mean velocity in the flow passages between adjacent fins. Figure 7 shows how $\theta$, the temperature difference between wall and bulk calculated from $Q_{n u m}$, decreases along the flow channel for various flow rates. Even at the lowest flow rate, the air temperature at outlet is substantially lower than the base plate temperature.

\section{Discussion}

For each theoretical approach it was assumed that the flow channels formed by the base plate and cooling fins were completed by a cover at the fin tips. In practice this is necessary to prevent cooling flow leakage from the heat sink and this also represented the system investigated experimentally by Teertstra et al. [1].

Provided that conduction in the fins was modelled, either using fin efficiencies or finite elements, there was reasonable agreement between the predictions for the various approaches. The increasing discrepancy with flow rate between $Q_{a p p r o x}$ and $Q_{n u m}$ can be understood from the variations of Nusselt number and fin efficiency calculated using equations (24) and (17), respectively, and shown in Figures 8 and 9, respectively. The higher flow rates generate higher heat transfer coefficients near the leading edges of the fins, which in turn produce significantly lower fin efficiencies.

Some comments must be made about the accuracy of the modelling for flows in real heat sinks. Firstly, thermal radiation from the heat sink has been neglected. This is probably a reasonable assumption; both emissivity and shape factor for the aluminium cooling fins would be relatively low and Teertstra et al. [1] demonstrated experimentally that thermal radiation contributed no more than $1 \%$ to overall heat transfer. Simple thermal radiation calculations for a grey body with black surroundings using representative emissivities (assuming isothermal boundaries for the heat sink at the base plate temperature) indicate a rate of radiation heat transfer of less than $2 \%$ of the convective heat transfer.

Free convection effects have also been neglected. The reason for this is that free convection heat transfer coefficients for surfaces within the flow channel would typically be six or seven times lower than that for forced convection. Heat transfer coefficients in laminar mixed forced-and-free convection are often combined [10,11] using an equation of the following form:

$$
h_{\text {mixed convection }}{ }^{n}=h_{\text {forced convection }}{ }^{n}+h_{\text {free convection }}{ }^{n}
$$

where the index $n$ typically has a value of between 3 and 7. For such a combination it is easily shown that buoyancy effects could not possibly influence the rate of heat transfer in this application. The influence of free convection can also be assessed from the Richardson number:

$$
R i=G r / \operatorname{Re}^{2}
$$


In conditions of mixed forced and free convection $\mathrm{Ri} \sim 1$, see for example [12]. Even at inlet for the lowest flow rate and hence the lowest Reynolds number combined with the maximum value of the Grashof number, the Richardson number is only of the order of $10^{-3}$. Hence we may safely neglect the free convection term in equation (30).

Other assumptions are less easy to justify. The heat transfer correlations used to calculate local Nusselt numbers in the analytical treatment, equations (16) and (24), were based on an analysis of simultaneously developing velocity and temperature in a flow with uniform wall temperatures, which had uniform velocity and temperature at the inlet. The velocity profile at inlet to the heat sink would almost certainly in reality be ill-defined; the blunt leading edges of the cooling fins would cause flow disturbance and modify the rate of heat transfer locally, although the effect would diminish downstream. Also, as demonstrated clearly by values obtained for the fin efficiency near the leading edge, the wall temperatures for the flow passage would not have been uniform. The finite element treatment of the cooling fins allows for heat conduction in the axial upstream direction, which is ignored when using a simple fin efficiency; rising wall temperatures in the direction of flow tend to increase heat transfer coefficients $[13,14]$. These two effects probably explain why the values for $Q_{C F D}$ are marginally higher than those for $Q_{a p p r o x}$ and $Q_{\text {num }}$.

In addition, all of the theoretical approaches have assumed laminar flow, although the Reynolds number for the higher flow rates analysed would probably have been in the transitional region rather than the laminar region. There is little information about the critical Reynolds number for transition from laminar flow to turbulent flow in a parallel-sided duct; a range of 2200 to 3400 has been suggested [15]. Half of the flows considered exceeded the lower limit of this range and two flows exceeded the upper limit.

Nevertheless, the predicted results are in very good agreement with the experimental data of Teertstra et al. [1]. Their experimental data were presented in graphical form but using different dimensionless groups. Teertstra et al. [1] based their Nusselt number $N u_{b}$ on the inlet temperature difference and took $b$ not $D_{h}$ to be the characteristic length. In their paper the flow was characterised by $R e^{*}$, a group identical to the reciprocal of $4 L^{*} P r$. When our predictions are represented by the same dimensionless groups and a curve is drawn through them, the line follows the variation of the experimental data very precisely, Figure 10.

Teertstra et al. [1] modelled the overall rate of heat transfer successfully by combining two expressions for mean Nusselt number empirically. The first expression described heat transfer at entry. The second (in the present authors' opinion described erroneously as "fullydeveloped") was based on the maximum rate of heat removal for a given flow (i.e. equation (13) with the exponential term negligible), when the air outlet temperature would be equal to the temperature of the base plate.

Various researchers have used the limit of the maximum rate of heat removal from a heat sink but it is not a particularly useful concept. As can be seen in Table 1 and Figure 7 the air outlet temperature did not approach the base plate temperature for the heat sink considered even for the lowest flow rate. Further, a heat sink with an air outlet temperature equal to the surface temperature does not represent an optimum design because much of the cooling fin would be operating with a small temperature difference and hence a low convective heat flux. Hence the cooling performance of much of the fin material would be poor and much of the fin material would therefore be wasted. It is also misleading to describe such a heat transfer condition as fully developed, since this state (a constant relationship between heat flux and temperature difference) is normally reached well before the temperature difference and heat flux decay to zero.

The present study provides a much more rigorous analysis and makes an interesting observation missed by previous researchers. Although increased complexity has 
progressively been introduced into the study, it is apparent that classical analytical heat transfer theory provides very acceptable engineering accuracy with good agreement with both experimental data and a full numerical simulation. The approach employs average values of heat transfer coefficient and fin efficiency, which are obtained from analytical expressions, and as a consequence the thermal performance of the heat sink can be assessed very rapidly. It is not necessary to resort to an empirical combination of limiting heat transfer cases, namely, heat transfer in the entry region and heat transfer for a very long heat sink [1]. There is also no need for a numerical integration along the flow passage using local values of heat transfer coefficient and fin efficiency [4].

\section{Conclusions}

Heat transfer conditions in the flow channels formed by the rectangular fins of a heat sink have been analysed using analytical, numerical and computational methods of varying complexity.

Initially results are presented for idealised fins which are 100\% efficient using an expression for mean Nusselt number to describe heat transfer conditions from entry to exit. Next a uniform fin efficiency based on this mean Nusselt number is utilised. More detail is then introduced by allowing both Nusselt number and fin efficiency to vary along the flow passage and by calculating air temperatures using numerical integration. Finally the effects of flow disturbance at entry to the heat sink and axial conduction in the cooling fins are modelled in a CFD study with a finite element treatment of the fins.

Good agreement has been obtained between all heat transfer predictions and experimental data of Teertstra et al. [1] except, of course, for those made assuming the fins to be at uniform temperature. Although the calculations show that heat transfer coefficients and fin efficiencies vary substantially along the flow path, good engineering accuracy for heat sink performance can be obtained for laminar flow using calculations in which mean values for the Nusselt number and fin efficiency are calculated from analytical expressions.

\section{Acknowledgement}

This work was part of a project funded by Solas Technology Limited, Ireland.

\section{Nomenclature}

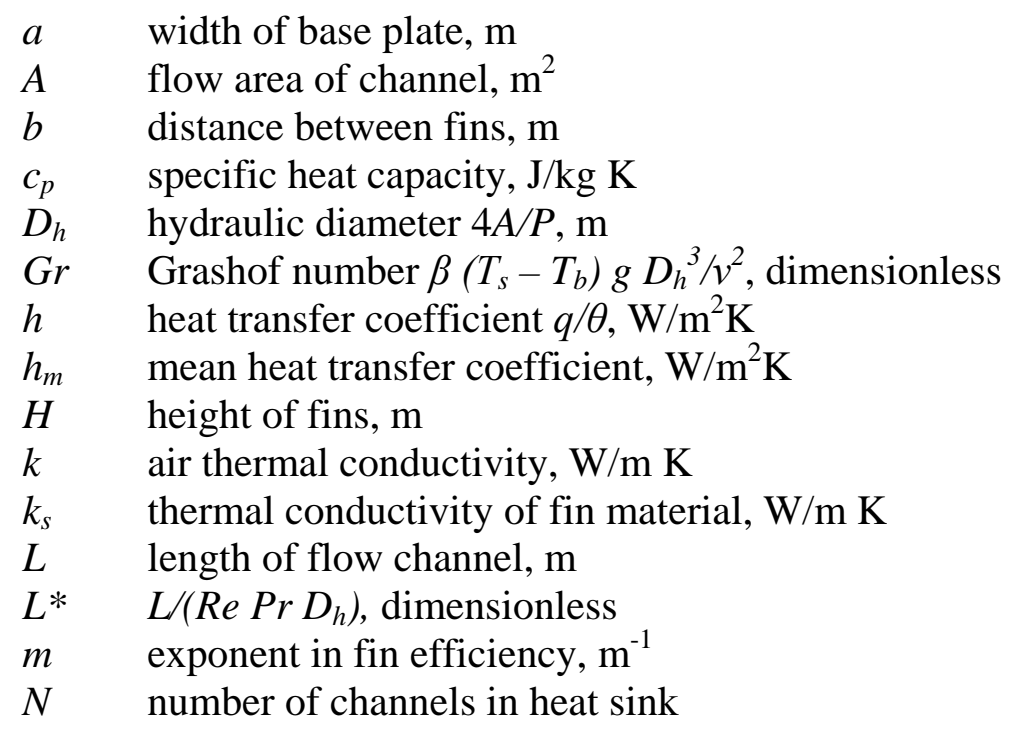


$\mathrm{Nu} \quad$ Nusselt number $h D_{h} / k$, dimensionless

$\mathrm{Nu}_{b} \quad$ Nusselt number based on the distance between fins and the inlet temperature difference $Q_{1} b /\left(2 k L H \theta_{0}\right)$, dimensionless

$\mathrm{Nu}_{x} \quad$ Nusselt number based on axial position $h x / k$, dimensionless

$N u_{m} \quad$ mean Nusselt number $h_{m} D_{h} / k$, dimensionless

$P \quad$ perimeter of flow channel, $m$

$\operatorname{Pr} \quad$ Prandtl number, dimensionless

$Q \quad$ rate of heat removal from heat sink, W

$Q_{1} \quad$ rate of heat transfer for a single channel, $\mathrm{W}$

$q$ heat flux, $\mathrm{W} / \mathrm{m}^{2}$

Re Reynolds number $u_{m} D_{h} / v$, dimensionless

$R e_{b}^{*} \quad$ Reynolds number as defined by Teerststra et al. [1] $u_{m} b^{2} / L v$, dimensionless

$R e_{x} \quad$ Reynolds number based on axial position $u_{m} x / v$, dimensionless

Ri Richardson number $G r / R^{2}$, dimensionless

$T_{b} \quad$ bulk temperature, ${ }^{\circ} \mathrm{C}$

$T_{s} \quad$ surface temperature for base plate, ${ }^{\circ} \mathrm{C}$

$t \quad$ thickness of cooling fin, $\mathrm{m}$

$U_{a} \quad$ approach velocity, $\mathrm{m} / \mathrm{s}$

$u_{m} \quad$ mean velocity in flow channel, $\mathrm{m} / \mathrm{s}$

$x \quad$ axial position in flow channel, $\mathrm{m}$

$x^{*} \quad X /\left(\operatorname{Re} \operatorname{Pr} D_{h}\right)$, dimensionless

$\beta \quad$ coefficient of expansion, $1 / \mathrm{K}$

$\eta \quad$ fin efficiency, dimensionless

$v \quad$ kinematic viscosity, $\mathrm{m}^{2} / \mathrm{s}$

$\theta \quad$ temperature difference $T_{s}-T_{b}, \mathrm{~K}$

$\rho \quad$ air density, $\mathrm{kg} / \mathrm{m}^{3}$

Subscripts

approx calculations made using a fin efficiency based on $N u_{m}$

CFD calculations made using a commercial CFD package

ideal calculations made assuming a fin efficiency of $100 \%$

$L \quad$ value at $x=L$

num numerical calculations with variable $\mathrm{Nu}$ and $\eta$

$0 \quad$ value at $x=0$

\section{References}

1. Teertstra, P., Yovanovich, M.M., Culham, J.R., and Lemczyk, T., 1999, “Analytical Forced Convection Modeling of Plate Fin Heat Sinks", Proc. $15^{\text {th }}$ IEEE Semi-Therm. Symposium, pp 34-41.

2. Duan, Z., and Muzychka, Y.S., 2006, "Experimental Investigation of Heat Transfer in Impingement Air Cooled Plate Fin Heat Sinks”, Trans. ASME J. Electronic Packaging, 128, pp412-418.

3. Shin, D., 1998, “Thermal Design and Evaluation Methods for Heat Sink”, Tech. Report. 7th International FLOTHERM User Conference Verona, Italy - T226

4. Bar-Cohen, A., and Iyengar, M., 2003, "Least-energy Optimization of Air-cooled Heat Sinks for Sustainable Development”, IEEE Transactions on Components and Packaging Technologies, 26, pp16-25. 
5. Kreith, F., and Bohn, M.S., 1993, Principles of Heat Transfer, $5^{\text {th }}$ edition, West Publishing Company, p. 270.

6. Shah, R.K., and Bhatti, M.S., 1987, "Laminar Convective Heat Transfer in Ducts”, in Kakaç, S., Shah, R.K., and Aung, W., Handbook of Single-Phase Convective Heat Transfer”, John Wiley \& Sons, page 3.31.

7. Hwang, C.L., and Fan, L.T., 1964, "Finite Difference Analysis of Forced Convection Heat Transfer in Entrance Region of a Flat Rectangular Duct”, Appl. Sci. Res., A13, pp401422.

8. Chapman, A.J., 1987, “Fundamentals of Heat Transfer”, Macmillan Publishing Company, p. 71.

9. Shah, R.K., and Bhatti, M.S., 1987, "Laminar Convective Heat Transfer in Ducts”, in Kakaç, S., Shah, R.K., and Aung, W., Handbook of Single-Phase Convective Heat Transfer”, John Wiley \& Sons, p. 3.42

10. Chen, T.S., and Armal, B. F., 1987, "Mixed Convection in External Flows”, in Kakaç, S., Shah, R.K., and Aung, W., Handbook of Single-Phase Convective Heat Transfer", John Wiley \& Sons, pp 14-1 - 14-35.

11. Aung, W., 1987, "Mixed Convection in Internal Flows”, in Kakaç, S., Shah, R.K., and Aung, W., Handbook of Single-Phase Convective Heat Transfer”, John Wiley \& Sons, pp 15-1 - 15-51.

12. Lienhard IV, J.H. and Lienhard V, J.H., 2001, A Heat Transfer Textbook $3^{\text {rd }}$ edn., Phlogiston Press, Cambridge, Massachusetts, USA, p.408.

13. Walker, V., and Rishehri, S.A., 1972, "Forced Convection in Parallel and Tapered Passages: the Importance of the Heat Flux Boundary Condition”, Int. J. Heat Mass Transfer, 15, pp 781-788.

14. Axcell, B.P., Tonge, D.A., and Jemsson, T., 1988, "Turbulent Forced Convection in a Pipe with an Exponential Wall Heat Flux", in Shah, R.K., Ganić, E.N., and Yang, K.T., Experimental Heat Transfer, Fluid Mechanics, and Thermodynamics, Elsevier, pp808815.

15. Shah, R.K., and Bhatti, M.S., 1987, "Turbulent and Transition Flow Convective Heat Transfer in Ducts”, in Kakaç, S., Shah, R.K., and Aung, W., Handbook of Single-Phase Convective Heat Transfer”, John Wiley \& Sons, p.4.59 


\section{List of Figures}

Figure 1: Arrangement of the heat sink

Figure 2: Flow through the channel

Figure 3: The studied model with boundary conditions

Figure 4: Temperature and velocity profiles along a central plane through the channel between two fins, $U_{a}=2 \mathrm{~m} / \mathrm{s}$

Figure 5: Velocity profile and the flow disturbance at the entrance region of the channel $\left(U_{a}=4 \mathrm{~m} / \mathrm{s}\right)$

Figure 6: Variation of $Q_{\text {ideal }}, Q_{a p p r o x}, Q_{n u m}$ and $Q_{C F D}$ with mean velocity

Figure 7: Variation of $\theta / \theta_{o}$ against $x / L$ for various flow rates

Figure 8: Variation of $\mathrm{Nu}$ against $x / L$ for various flow rates

Figure 9: Variation of $\eta$ against $x / L$ for various flow rates

Figure 10: Comparison between the approximate analysis and the data of Teertstra et al. [1] 


\section{List of Tables:}

Table 1: Thermal Performance of Heat Sink 

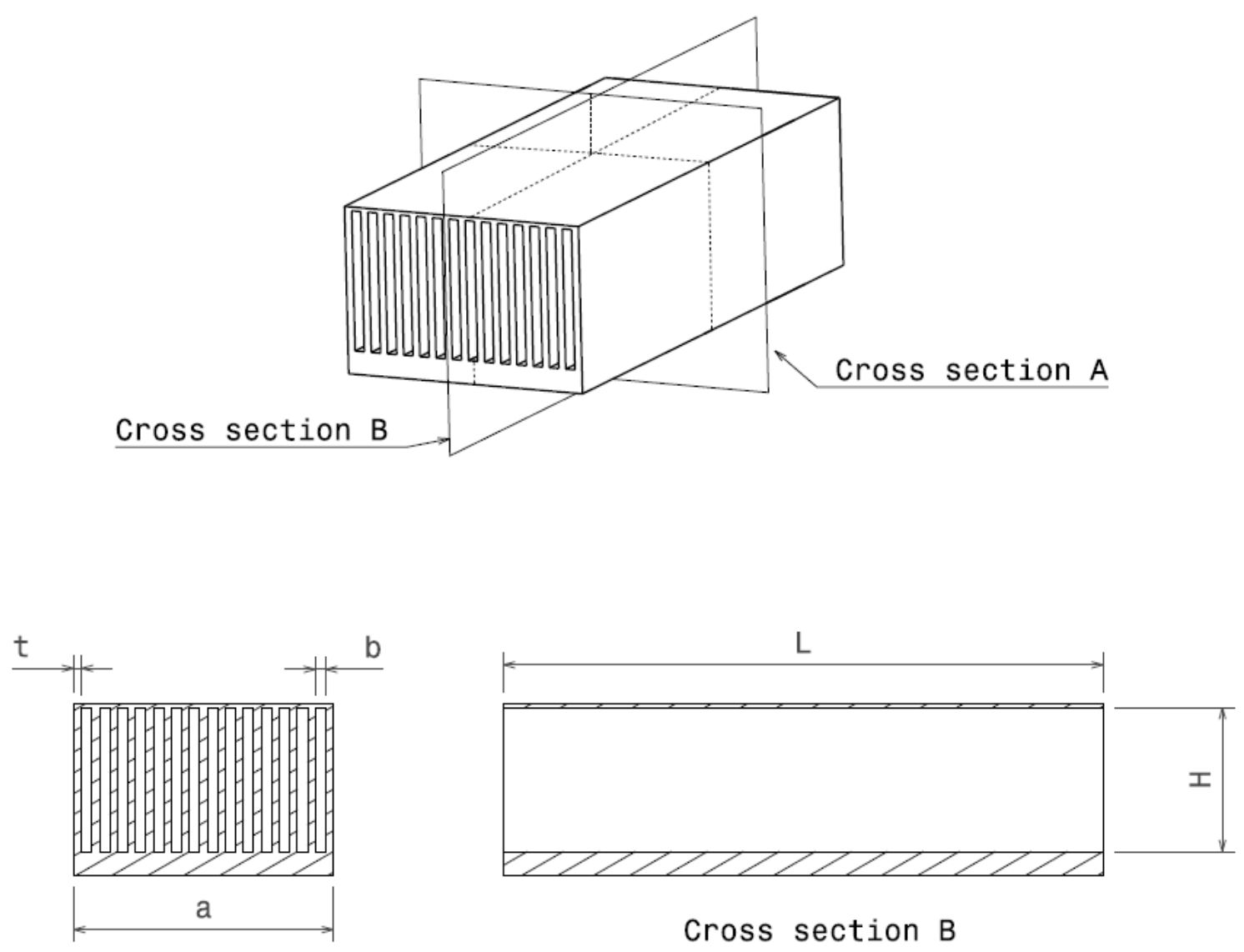

Cross section A

Figure 1: Arrangement of the heat sink 


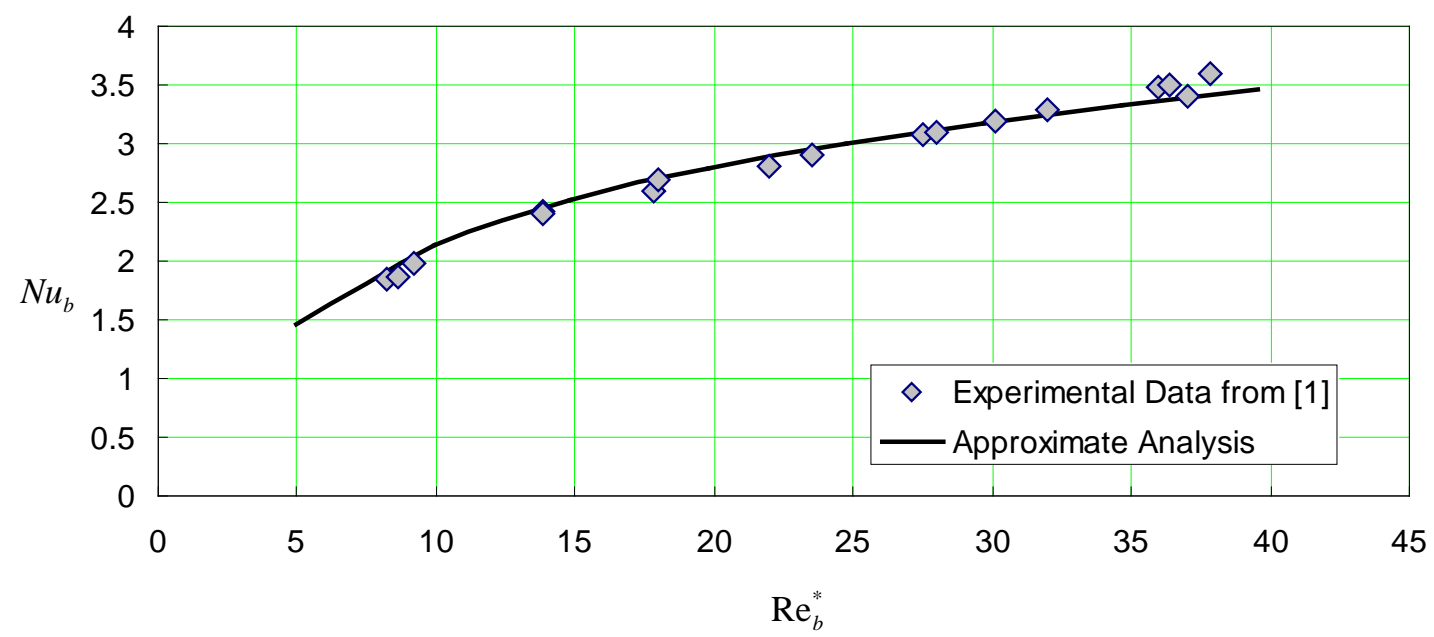

Figure 10: Comparison between the approximate analysis and the data of Teertstra et al. [1]. 


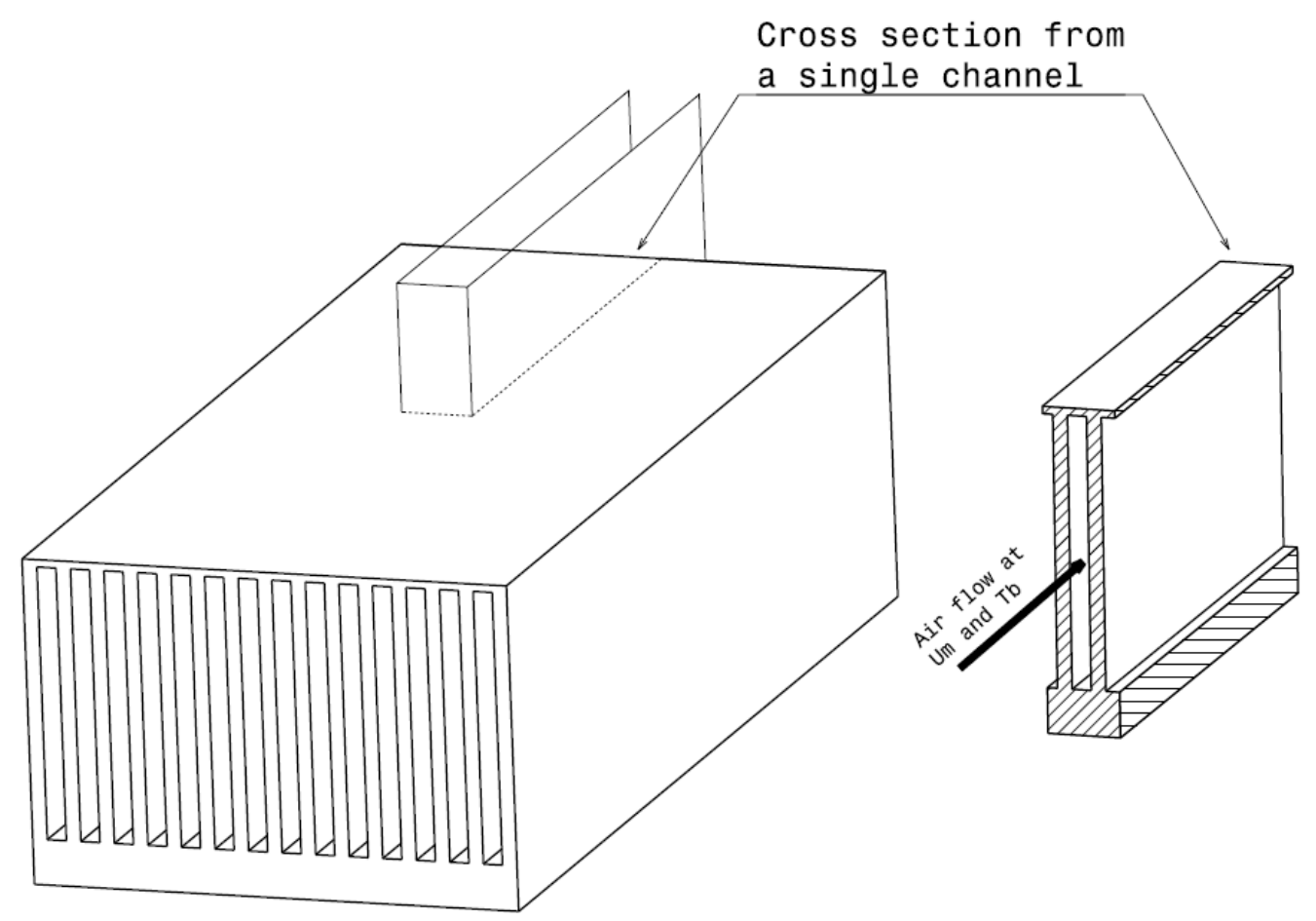

Figure 2: Flow through the channel 


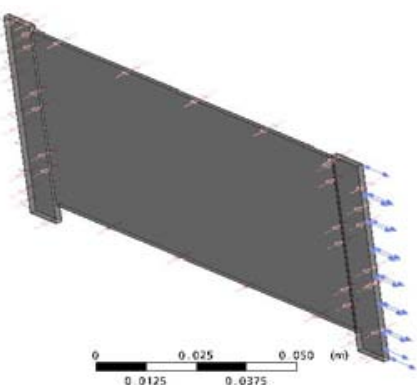

I: Air (Fluid) Domain of the CFX analysis onto which boundary conditions were applied.

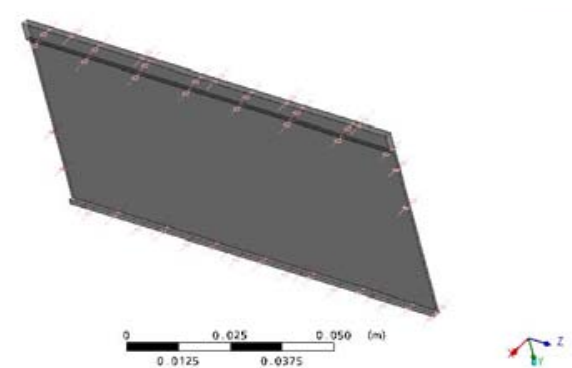

II: Fin (Solid) Domain of the CFX analysis onto which boundary conditions were applied.

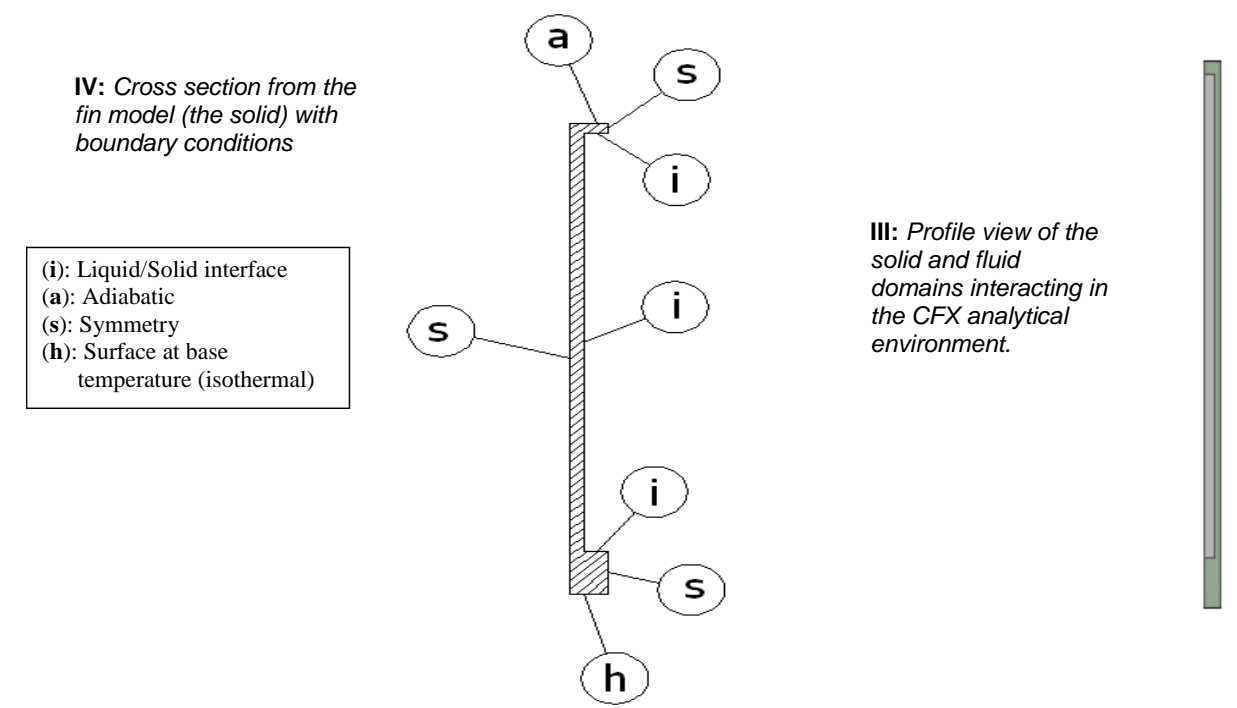

Figure 3: The studied model with boundary conditions 

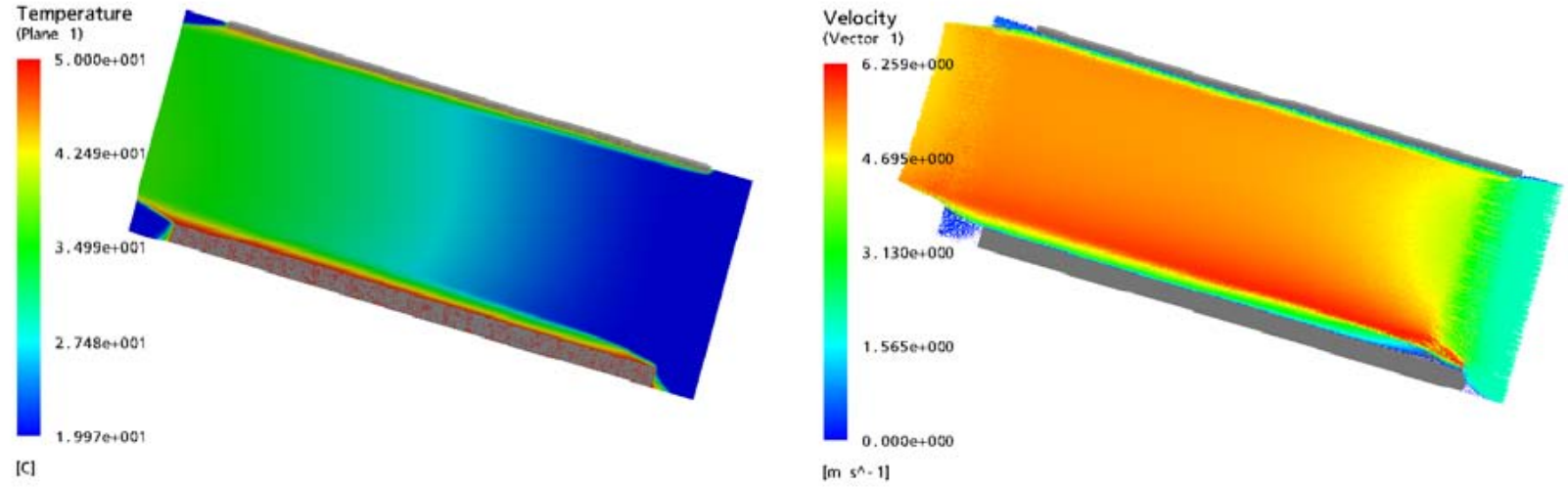

Figure 4: Temperature and velocity profiles along a central plane through the channel between two fins, $U_{a}=2 \mathrm{~m} / \mathrm{s}$ 


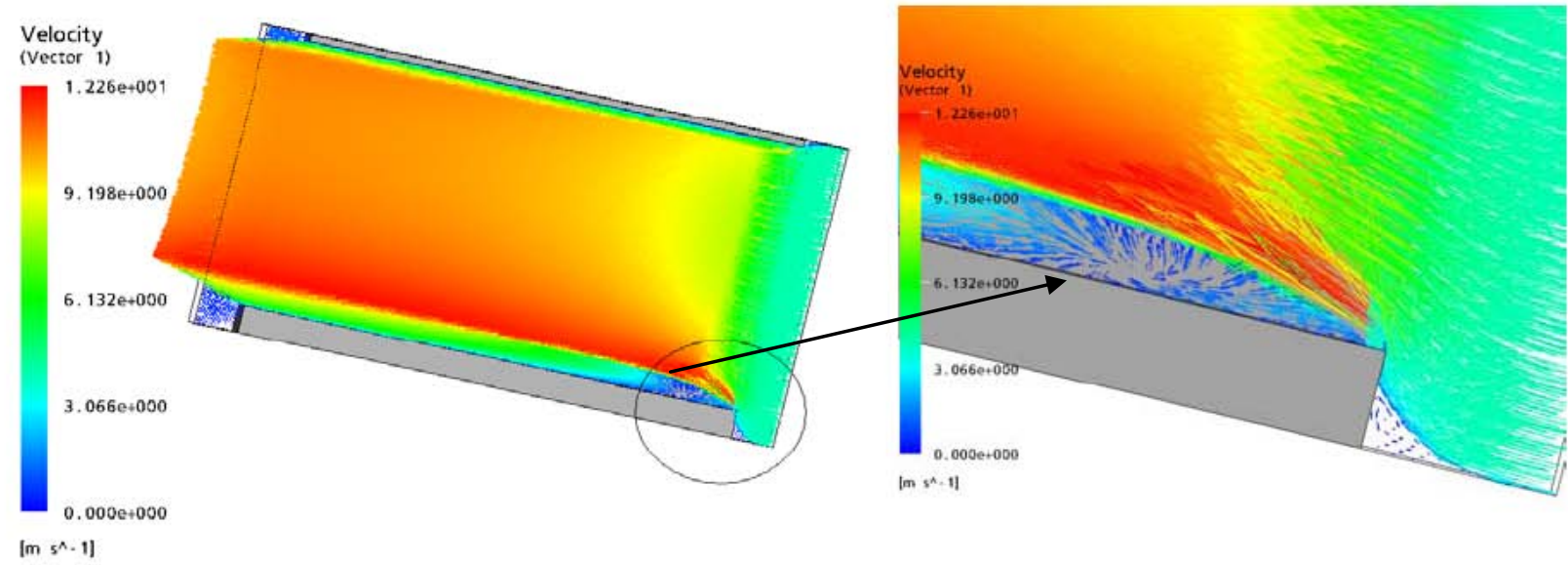

Figure 5: Velocity profile and the flow disturbance at the entrance region of the channel $\left(U_{a}=4 \mathrm{~m} / \mathrm{s}\right)$ 


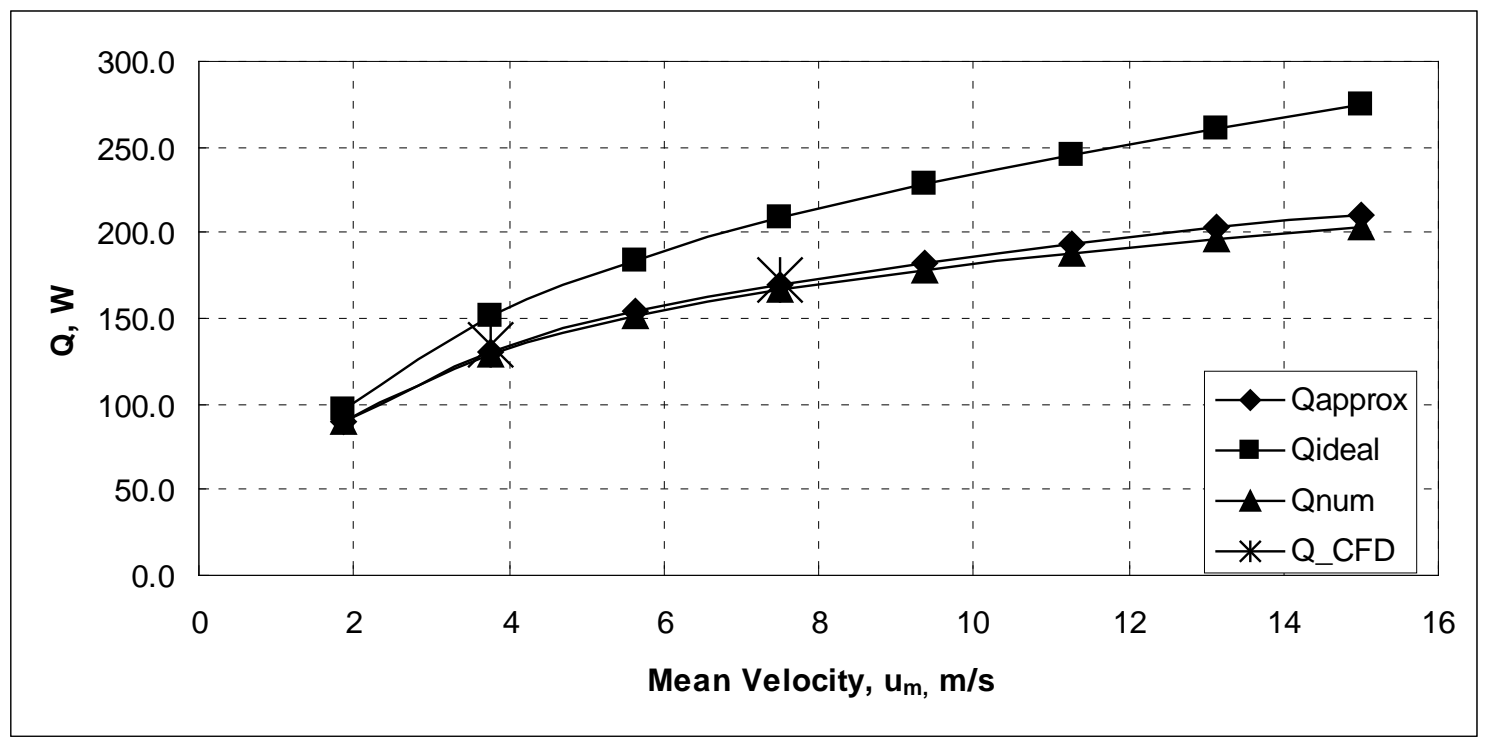

Figure 6: Variation of $Q_{\text {ideal }}, Q_{a p p r o x}, Q_{n u m}$ and $Q_{C F D}$ with mean velocity 


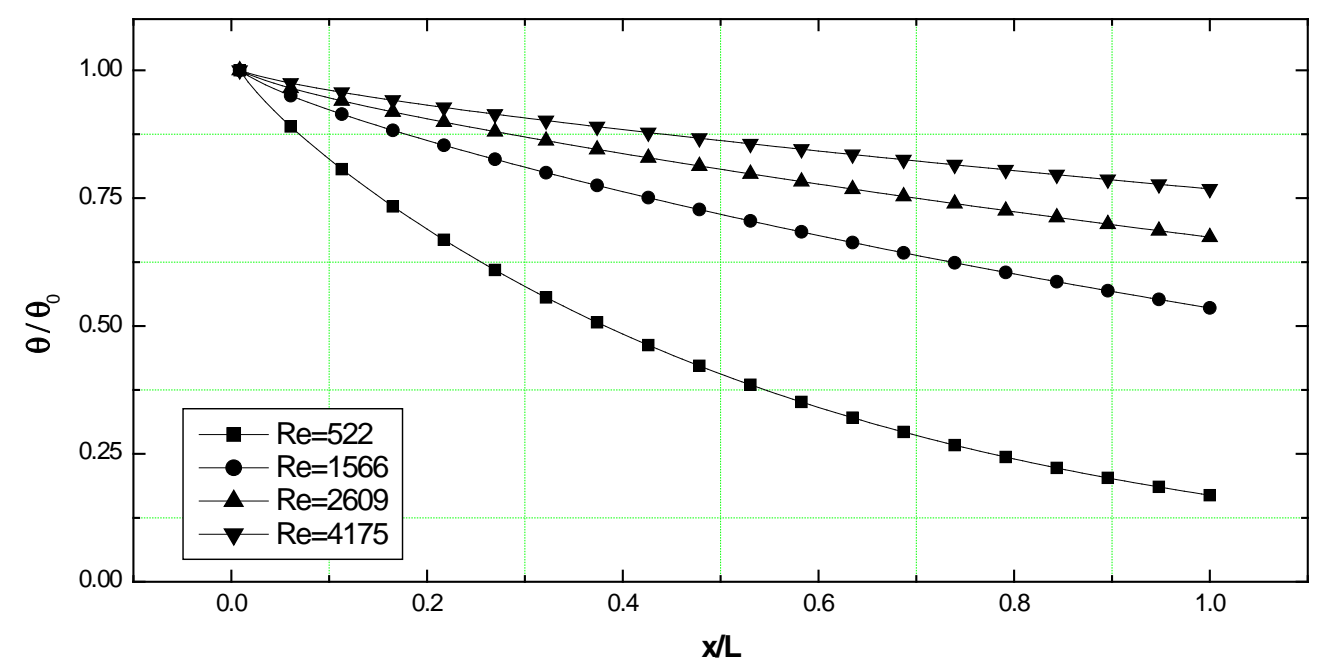

Figure 7: Variation of $\theta / \theta_{o}$ against $x / L$ for various flow rates 


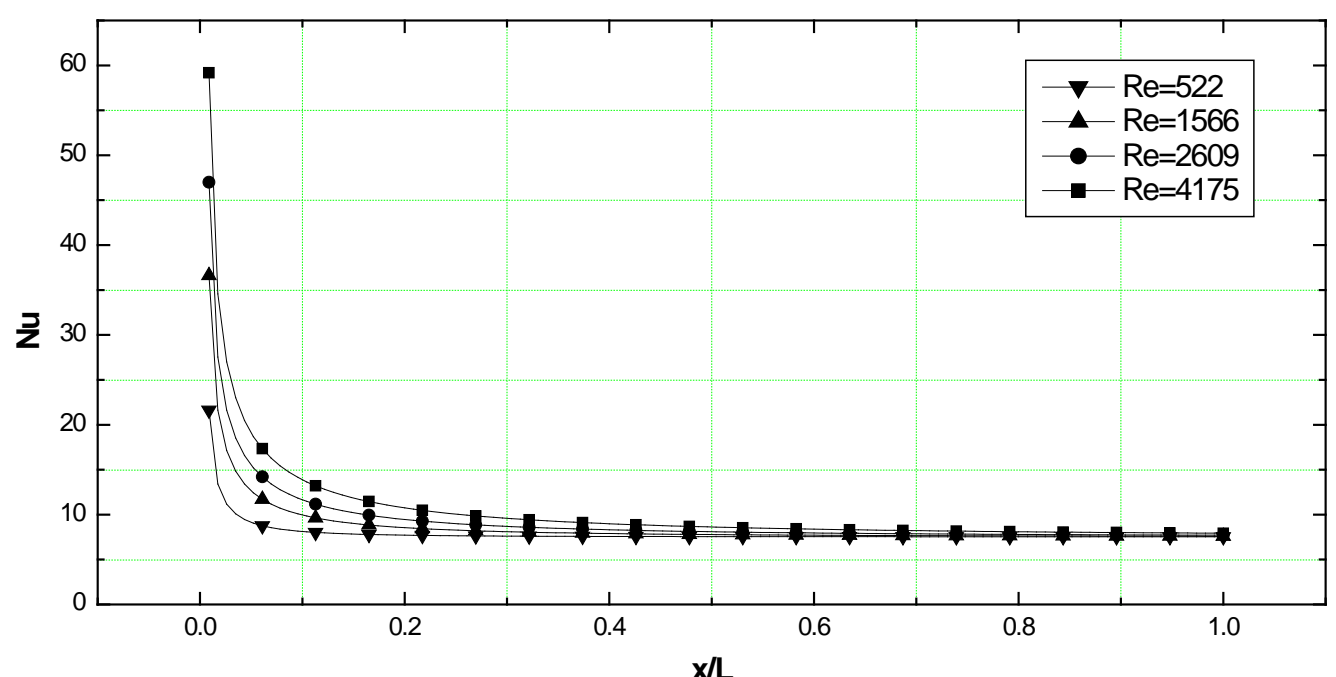

Figure 8: Variation of $N u$ against $x / L$ for various flow rates 


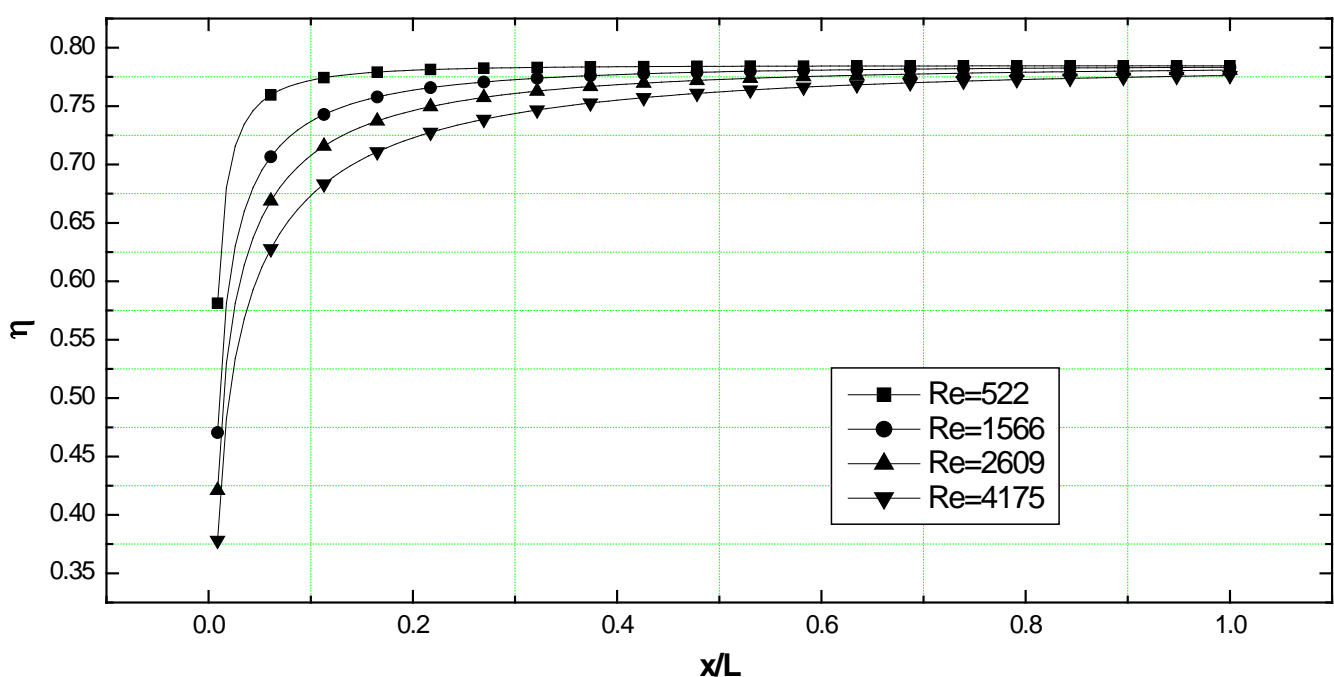

Figure 9: Variation of $\eta$ against $x / L$ for various flow rates 
Table 1: Thermal Performance of Heat Sink

\begin{tabular}{|c|c|c|c|c|c|c|c|c|c|}
\hline $\begin{array}{c}U_{a} \\
(\mathrm{~m} / \mathrm{s})\end{array}$ & $\mathrm{u}_{\mathrm{m}}(\mathrm{m} / \mathrm{s})$ & $R e$ & $N u_{m}$ & $\begin{array}{c}Q_{\text {ideal }} \\
(\mathrm{W})\end{array}$ & $\eta_{m}$ & $\begin{array}{c}Q_{\text {approx }} \\
(\mathrm{W})\end{array}$ & $\begin{array}{c}Q_{\text {num }} \\
(\mathrm{W})\end{array}$ & $\begin{array}{c}Q_{C F D} \\
(\mathrm{~W})\end{array}$ & $\begin{array}{c}T_{L} \\
\left({ }^{\circ} \mathrm{C}\right)\end{array}$ \\
\hline 1 & 1.88 & 522 & 7.96 & 96.3 & 0.776 & 89 & 89 & & 45.1 \\
\hline 2 & 3.75 & 1044 & 8.38 & 150.7 & 0.676 & 131 & 129 & 135 & 38.2 \\
\hline 3 & 5.63 & 1566 & 8.79 & 184.2 & 0.759 & 154 & 151 & & 34.2 \\
\hline 4 & 7.51 & 2088 & 9.18 & 208.7 & 0.751 & 170 & 166 & 172 & 31.7 \\
\hline 5 & 9.39 & 2610 & 9.56 & 228.5 & 0.744 & 183 & 178 & & 30.0 \\
\hline 6 & 11.3 & 3132 & 9.93 & 245.5 & 0.737 & 193 & 187 & & 28.8 \\
\hline 7 & 13.1 & 3653 & 10.28 & 260.7 & 0.731 & 203 & 196 & & 27.9 \\
\hline 8 & 15.0 & 4175 & 10.62 & 274.6 & 0.725 & 211 & 203 & & 27.1 \\
\hline
\end{tabular}

